\title{
$1 \quad$ Hazards threatening underground transport systems
}

2 Edwar Forero-Ortiz ${ }^{\mathrm{a}, \mathrm{b} *}$, Eduardo Martínez-Gomariz ${ }^{\mathrm{a}, \mathrm{b}}$

3 C CETaqua Water Technology Centre, Barcelona, Spain. ORCID 0000-0002-5238-278X

$4 \quad{ }^{b}$ Flumen Research Institute, Civil and Environmental Engineering Department, Technical University of 5 Catalonia, Spain. ORCID 0000-0002-0189-0725

6 *Corresponding author. Email: eaforero@ cetaqua.com

7

8

9

\begin{abstract}
Metro systems perform a significant function for millions of ridership worldwide as urban passengers rely on a secure, reliable, and accessible underground transportation way for their regular conveyance. However, hazards can restrict normal metro service and plans to develop or improve metro systems set aside some way to cope with these hazards. This paper presents a summary of the potential hazards to underground transportation systems worldwide, identifying a knowledge gap on the understanding of water-related impacts on Metro networks. This is due to the frequency and scope of geotechnical and air quality hazards, which exceed in extreme magnitude the extreme precipitation events that can influence underground transportation systems. Thus, we emphasize the importance of studying the water-related hazards in Metro systems to fill the gaps in this topic.
\end{abstract}

Keywords: urban climate adaptation; hazards assessment; critical infrastructure networks; metro system; subway. 


\section{Introduction}

The globalization process has grown these last sixty years, considering as Africa and Asia are urbanizing quicker than the rest of the continents in the coming decades. (UN 2018). As shown in Figure 1, projections indicate a growth of the world's urban population by more than two thirds by 2050, with almost 90 per cent of that increase in urban areas of Asia and Africa.

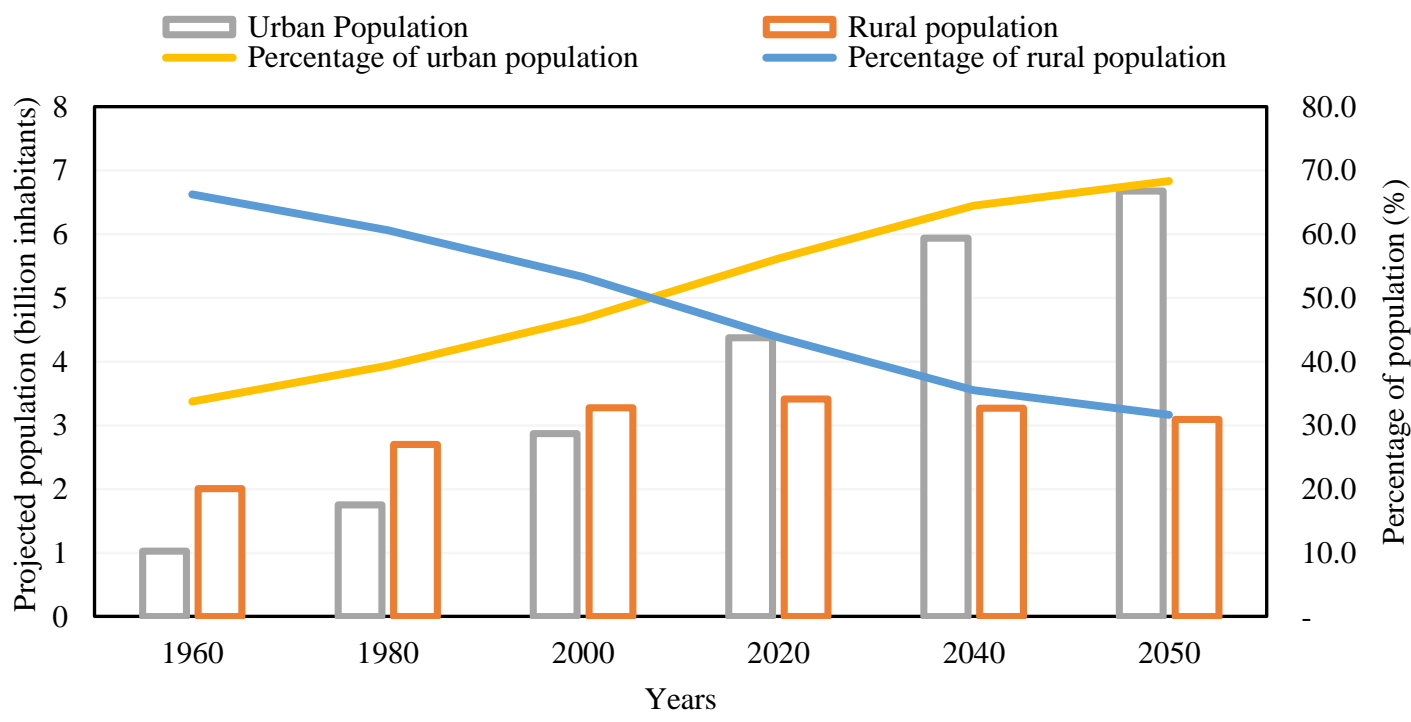

25

Figure 1. Historical and projected evolution of the urban population compared to the world's rural population, 1960 to 2050 (UN 2018).

A wide range of environmental hazards including extreme weather events, droughts, biodiversity loss and stress on natural resources are impacting on cities worldwide. The most significant hazards rank since 2011 concerning probability and global impact are the extreme weather events and the lack of adaptation to climate change.

Therefore, current trendlines involve encouraging shifts in priorities at the governmental and private levels, focus on vulnerable growing cities to the impact of climate change (WEF and Collins 2019).

Urban areas can be considered as living organisms, comprising several interdependent sectors and activities, intimately connected as services. Climate change requires cities to mitigate several hazards in the short term, yet they must develop their potential to improve their resilience (Kim and $\operatorname{Lim} 2016)$.

To achieve cities sustainability, we need to analyse urban resilience. Given the growing people and resources concentration on urban environments, as the increasing frequency and intensity of risks that threaten their services, the cities life cycle should be examined. (Sharifi and Yamagata 2018). Urban resilience, as a city system recovery potential facing different hazards, becomes 
relevant taking into account service interruptions worsened by climate change next century.

44 (Velasco et al. 2018).

The interdependence linking the city services, such as water, energy, and public transport as critical infrastructure networks, has increased due to technological advances in recent decades. This bond has generated incremental improvements in essential city services quality and coverage, but a worsened status when a natural hazard event occurs impacting the service operational viability. Subsequent, the failure across the network of critical infrastructure services spread, known as cascade effects (Evans et al. 2018).

One of the most critical services for the proper functioning of a city is public transport networks. According to the International Association of Public Transport (UITP), the year 2015 noticed an $18 \%$ increase in public transport trips compared to 2000, with 243 billion trips made in 39 countries (UITP and Saeidizand 2015).

The backbone of urban mobility is well-integrated high-capacity public transport systems into a multimodal arrangement. In both developing and developed countries, most maintain or increase the market share of formal public transport (United Nations Human Settlements Programme 2013).

Due to the increase in population and awareness to achieve a lower economic, environmental, and social impact, cities worldwide are implementing public and non-motorized transport systems as Metro networks. Sustainable transport systems have a positive correlation with GDP, while vehicle use improves economic and social parameters, albeit with a negative impact on the urban environment (Haghshenas and Vaziri 2012).

The accelerated metro systems development since the 1960s responding to mega-cities growth shows their importance holding public mobility in urban areas. Metro infrastructure is less bottlenecks-prone than roadways and mitigates long distances to urban activity nodes for the population living in peripheral locations. (United Nations Human Settlements Programme 2013).

According to the cities stimulated growth, consequently, of their metro systems, the higher the growth and metro network complexity, the higher the vulnerability to natural hazards (Sun and Guan 2016).

Metro systems concentrate the corridors with the highest volume/length of travel and the greatest activity centres in the cities (Yang et al. 2015). Underground transport systems are an essential part of the urban lifestyle, as passengers rely on a safe, reliable and accessible system for their regular transportation (Mohammadi et al. 2019). 
A variety of definitions of the term "Metro" are accepted such as subway, underground or tube, among others. Throughout this document, the term 'Metro system' is used to refer to high capacity underground urban railway systems, which are operated under an exclusive right of way, using the definition suggested by UITP (2018).

In its report World Metro Figures 2018, UITP (2018) summarizes some facts of urban underground transport systems. They operate in 178 cities, 56 countries by 2018, carrying 168 million passengers per day on average with a $19.5 \%$ annual ridership increase worldwide.

However, to date, no conclusive research is known on metro systems general data, such as typology (size, configuration, passengers' number, depth, length), tunnels and infrastructure administrative, economic, and physical sustainability. Or even, a hazards summary which threatens metro systems as important issues; most studies in underground transport systems have just focused on confined conditions.

This document provides a comprehensive and systematic review of studies on risk assessment for underground transport systems, exploring the impact sources and existing assessment methodologies.

The general structure of this literature review has five sections; the introduction presents how underground transport systems such as metro respond to urban population growth dynamics and natural hazards they face, highlighting the importance of this research.

The second part presents the methodology implemented for this literature review. Section three introduces risk and resilience in transport systems concepts and the link within facing natural hazards and developing urban resilience. Section four begins by laying out the knowledge dimensions of threat categorization research for Metro systems. The closing section examines the results of the literature review.

\section{Methodology}

The methodological approach adopted in this article is a mixed methodology based on the work of the PRISMA Group (Moher et al. 2009a), whose effort provides a reliable method for performing a literature review and is used in similar studies, such as Eckhardt et al. (2019). Figure 2 provides the summary of the performed approach.

Literature review first step establishes the relevance of urban transport systems as a key component, offering a proper integrated operation. Due to the lack of information natural hazard adaptation measures in metro systems, a significant part of the available information comes from sources other than academic publications and distribution channels (e. g., newspapers and reports) mainly known as grey literature. 


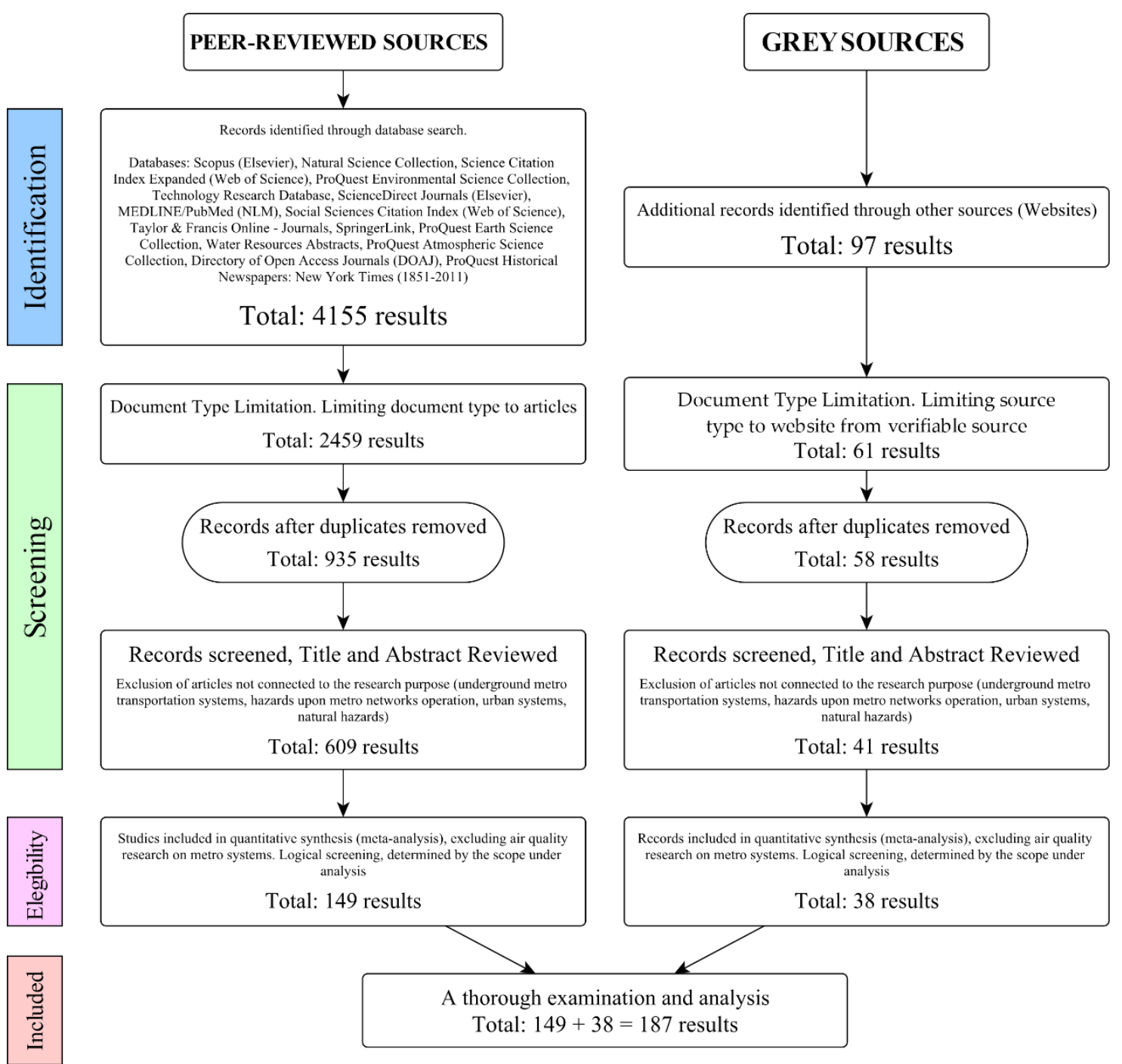

Figure 2. Literature review output summary. Adapted from the PRISMA Statement (Moher et al.

111 Collecting, organizing and analysing information processes applies relevant keywords 112 determination to avoiding bias, similar but unrelated sources to the under investigation topic, and 113 other source limitations. ¿Error! No se encuentra el origen de la referencia. presents this 114 information along with the eligibility criteria of the data sources.

\begin{tabular}{|c|c|c|}
\hline $\begin{array}{l}\text { Research } \\
\text { component }\end{array}$ & Criteria establishment procedures & Definition \\
\hline \multirow{4}{*}{ Research keywords } & $\begin{array}{l}\text { - Description on the keywords generally used to } \\
\text { describe hazardous events provoked by nature }\end{array}$ & • $\quad$ "hazard" in any field \\
\hline & $\begin{array}{l}\text { Definition according to the inclusion of } \\
\text { synonyms or other words applied to describe } \\
\text { underground transport systems. }\end{array}$ & $\begin{array}{l}\text { • } \quad \text { "subway", OR "underground", OR "metro" } \\
\text { in any field }\end{array}$ \\
\hline & $\begin{array}{l}\text { Exclusion of results related to anthropogenic } \\
\text { hazards, such as terrorism }\end{array}$ & • $\quad$ NOT "terrorism" \\
\hline & $\begin{array}{l}\text { Exclusion of the results related to the } \\
\text { construction stage of Metro systems }\end{array}$ & $\begin{array}{l}\text { - NOT "construction" - for instance, } \\
\text { excavation of Urban Subway Tunnel }\end{array}$ \\
\hline
\end{tabular}




\begin{tabular}{|c|c|c|}
\hline $\begin{array}{l}\text { Research } \\
\text { component }\end{array}$ & Criteria establishment procedures & Definition \\
\hline \multirow{5}{*}{$\begin{array}{l}\text { Peer-reviewed } \\
\text { sources - Grey } \\
\text { sources }\end{array}$} & $\begin{array}{l}\text { - Research that examines the hazard impact } \\
\text { assessments in Metro-type urban underground } \\
\text { transport systems. }\end{array}$ & $\begin{array}{l}\text { - Studies delimited to the definition of Metro } \\
\text { as an underground urban railway transport } \\
\text { system different from suburban trains or } \\
\text { tram systems }\end{array}$ \\
\hline & \multirow{4}{*}{ - Documents not related to the research purpose } & $\begin{array}{l}\text { - Health and safety hazards associated with } \\
\text { the Metro system }\end{array}$ \\
\hline & & $\begin{array}{l}\text { - Noise levels associated with the Metro } \\
\text { system }\end{array}$ \\
\hline & & $\begin{array}{l}\text { - Generalization of hazards in metropolitan } \\
\text { areas }\end{array}$ \\
\hline & & $\begin{array}{l}\text { - Simulations of evacuation behaviour during } \\
\text { a disaster in the Metro system }\end{array}$ \\
\hline
\end{tabular}

Table 1. Eligibility criteria for research components

\section{Access to vulnerability and resilience concepts in underground transport systems}

Due to practical constraints, this paper cannot provide a comprehensive review of the risk and resilience concepts in transportation systems, this study has only considered the context of risk and resilience concepts in underground transportation systems.

In a comprehensive literature outline of resilience concept, Wan et al. (2018) identified how growing complexity and unpredictability in transport schemes expose systems to disruptions and risks, varying from natural hazards, such as earthquakes, sea level rising and extreme storms, to critical anthropogenic events such as terrorist attacks and strikes. Also, it defined a summary of discussions and interpretation of terms linked to resilience.

Several studies, in particular, Sun and Guan (2016) discuss the exposure of the metro system operation and summarize the different methods for metro vulnerability assessment. The graphical network theory is the preferred method to perform theses analysis, taking into account the specific topological conditions of the metro system such as passenger flows, length and station capacity, with dynamic traffic redistribution after any failure or attack (Xing et al. 2017).

One of the most used approaches to assess the vulnerability of underground transport services is the service interruptions effects simulation, besides the evaluation of the system-critical elements under demanding conditions (Rodríguez-Núñez and García-Palomares 2014).These studies outline a critical role for passenger flow as a key factor in assessing metro systems vulnerability. In the same vein, Mattsson and Jenelius (2015) are interested in issues related to a better risk description, such as "a scenario description, the probability and the consequences (a measure of 
137 damage) of that scenario" in transportation system operations. This view goes beyond the

138 traditional description of risk as the product of probability and consequence.

139 Resilience and risk curve generation complexity is highlight due to unreliability and vulnerability

140 estimation differences, as risk probability functions in transportation systems. In recent years,

141 available methods have attempted to identify critical nodes in metro networks when assessing the

142 system disruptions impact (M'Cleod et al. 2017).

143 On the other hand, multiple studies have compared many approaches that evaluate the resilience

144 of current city public transport systems because of their critical importance. Approaches such as

145 that established for the London Underground (D'Lima and Medda 2015) relate the time it may

146 take for the system to recover. However, such approaches do not consider the complexities of

147 natural hazards such as an extreme rainfall event.

148 As Zhang et al. (2018) conclude, the studies reviewed set a general framework to create a metro

149 system resilience analysis, which studies the network stations connectivity and recovery

150 procedures after network disruptions.

151 Nevertheless, such studies remain limited in their approach that deals with resolving transport

152 network disruptions. Considering the current and future interdependencies linking the several city

153 services, cascading effects generated by metro system disruptions can affect diverse urban

154 services, indicating needs for additional research to evaluate integrated urban resilience such as

155 the European Project "RESCCUE” (Velasco et al. 2018).

156 Table 2 summarizes the review of the literature on the components of resilience and vulnerability.

157 As concepts widely implemented in various contexts, this research only covers these notions for 158 metro systems. 


\section{Source classification}

criterion

State-of-the-art review on transport system resilience

Resilience associated-

stochastic metrics

Step-by-step algorithm for

resilience estimation

Grid-based (or node)

vulnerability analysis

Resilience in response to

terrorist attacks

\section{Summary}

Source

This paper introduces a systematic review of transport resilience with an accent on its descriptions, features and analysis techniques employed in several transport operations. It identifies how reliable transport plays an essential role as a central part of global activities. Within the framework of the "RESOLUTE" project, funded by the EU, this paper examines the methodologies and applications of resilience management for transport systems in several countries, comparing and analysing the impacts of disturbances.

This paper discusses vulnerability and resilience definitions with related concepts, recognising two diverse ways to study the topic, first, studying transport vulnerability through graph theory, second, demand and supply representation sides. It identifies how short is literature on transport resilience, concerning the response and recovery periods after a failure.

This paper suggests a comprehensive conceptual framework aimed at expanding the network resilience concept within transport safety at different scales.

This paper introduces a resilience measure by presenting a systems' recovery quantification speed from disruptions, employing a meanreverting stochastic model to analyse the interruptions diffusive effects and implement this model to London Underground case.

This paper aims to estimate metro network vulnerability studying disruption from line operation viewpoint using the Shanghai metro network as case research. Results present recommendations on metro system administration for an operational performance potential increase and ridership having an enhanced alternative system when a disruption befalls.

This paper proposes a network model for the New York City subway system with a strategy based on passenger flow simulations on the shortest path to quantify the setbacks suffered by passengers that appear because of disturbing events, mainly those that occur simultaneously, determining separate disturbance scenarios and their results.

This paper develops a methodology for estimating public transport network vulnerability, applied to the Madrid Metro system. The study involves disruption consequences in riding times or trips number lost for the entire system with a complete GIS exploration approach.

Results show critical links where has low line density and the high ridership number, noticing the circular line importance as a network robustness factor.

This paper studies terrorist attacks occurrences against metro systems, aiming to decrease attacks number by lessening the transport systems attractiveness as a target, within the European FP7 project SecureMetro. This paper defines critical systems and recommends enhancements to metro carriages design, to increase emergency management capacity, learning from the experience of London underground bombings and other emergencies.
(Wan et al. 2018)

(Gaitanidou et al.

(Mattsson and Jenelius 2015)

(Reggiani 2013)

(D'Lima and Medda 2015)

(Sun and Guan

(M'Cleod et al.

(Rodríguez-Núñez and García-

Palomares 2014)

(Bruyelle et al. 2014) 
Transport systems

vulnerability and resilience

to cope with flood hazards,

sea level rise and sea storm

surge

Multi-valued resilience and dependency graph

frameworks
This paper provides an analysis of guided transport systems resilience to flooding hazards through failure mechanisms analysis. By applying operational safety methods and concepts and software design is feasible to anticipate all disruption scenarios and domino effects. This paper provides a vulnerability characterization methodology for guided transport systems facing natural hazards and to associate vulnerability depending on whether the system is in an underground, ground-level, or surface arrangement.

This study establishes a graphical interdependency model based on Bayesian network and the Delphi method for dynamic assess the factors determining fire conditions, fireproof/intervention measures, and fire consequences outcomes in metro stations. This research proposes insights into a practical examination for emergency decision-making toward fire emergency reduction considering the limited

\section{Table 2. Literature review on metro systems resilience and vulnerability components}




\section{An overview of hazards categorization for metro systems}

162 Figure 3 shows the identified hot spots and trend lines of current research on natural hazards and vulnerabilities in urban metro transport systems. This research uses the CiteSpace visualization and bibliographic analysis software (Chen et al. 2010) for two purposes. First, it generates an accurate picture, with their importance, of the approaches applied in metro systems natural hazards and vulnerabilities research; and second, it identifies current research potential gaps.

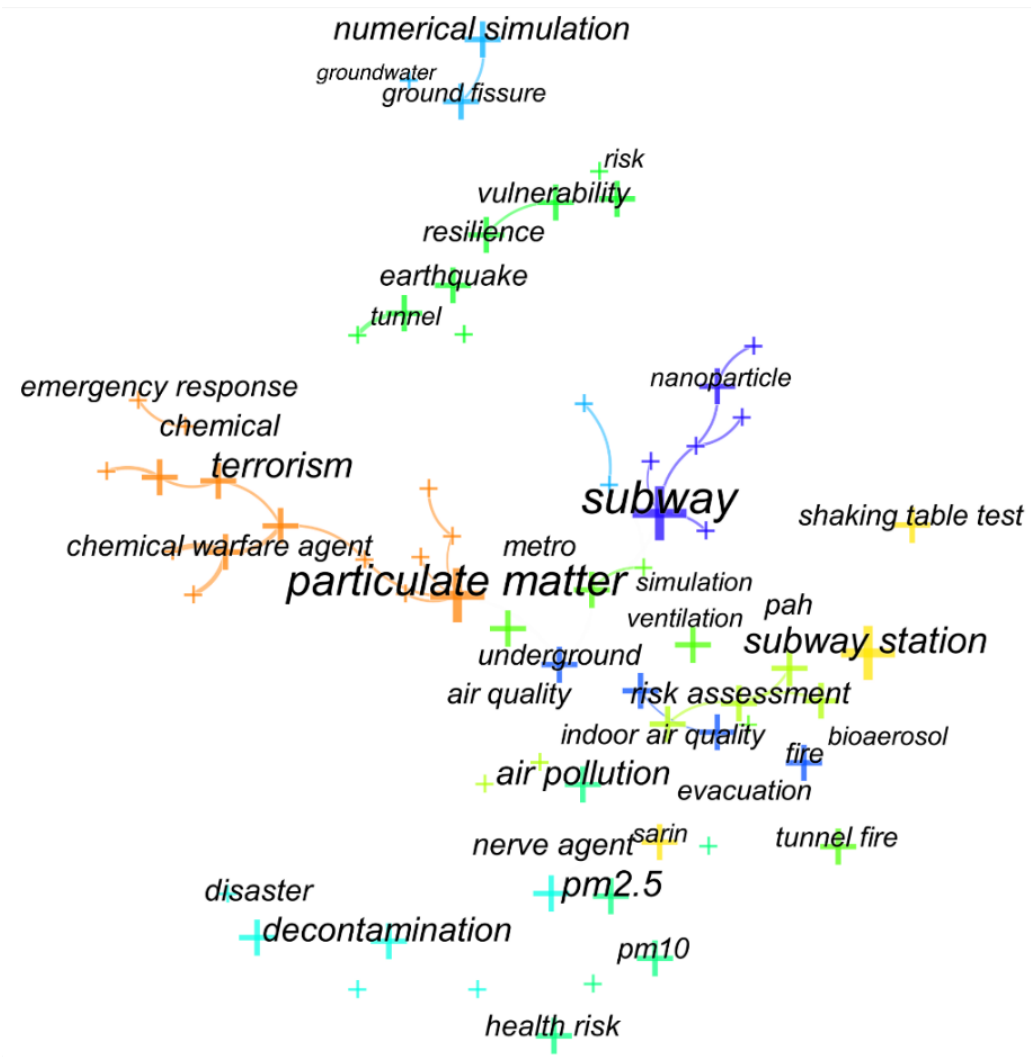

Figure 3. The visualized networks of co-keywords with highest occurrence frequency. Diagram based on pathfinder network scaling and co-citation analysis theory (Chen et al. 2010)

The application of Table 1 filters to improve the results is not possible in all cases, so some issues appear outside the context of this research (e.g., terrorism) as Figure 3 shows. Despite these

172 limitations, Figure 3 represents a comprehensive review of the most important research keywords 173 related to natural hazards on metro systems for current peer-reviewed sources.

174 Recognize knowledge groups importance and weight within scientific publications related to this 175 study area is perform by graphical analyses of the keywords association. Figure 3 highlights the 176 predominance of air quality risk research affecting metro systems, showing how the role of 177 particulate matter and air pollution has received increased attention in various research settings in recent years. 
179 Five important research topics emerge from the literature review so far focusing on hazards to

180 metro infrastructure: a) air quality, as airborne particulate matter; b) geohazards, expressed by

181 ground fissures and seismic impacts; c) geohazards, expressed by groundwater flows; d) water-

182 related hazards such as pluvial or river flooding; and, e) fire risks with smoke management. By

183 far, to date, water-related hazards in metro networks have received limited attention in the

184 research literature.

185 This document, as metro systems hazard comprehensive review, covers many recent studies focus

186 on metro stations fire hazards. We skim 545 articles in relevant journals between 2009 and 2019.

187 Numerous studies have attempted to explain how to improve air quality in metro systems

188 including detailed reviews of 160 major studies from over 20 countries were thoroughly examined

189 by Xu and Hao (2017). For example, a major fieldwork project on air quality in metro stations

190 was the EU-funded IMPROVE LIFE project (Moreno et al. 2014, 2015b, a, 2018; Martins et al.

191 2015, 2016; Moreno and de Miguel 2018; Spanish Research Council 2018).

192 Geological hazards are within the typologies of hazards that may threaten metro systems. Much

193 of the available literature (Dashko 2016; Wu et al. 2018c) deals with planning and construction

194 phases since metro stations settlements during excavations are highly subject to geotechnical

195 problems and the influence of the water table (Raben-Levetzau et al. 2004). As this literature

196 review disregards the metro systems development phase hazards, these research types are not

197 addressing here.

198 This study identifies a gap in the literature, intending to understand how flooding events in the 199 metro system generate economic and social impacts through metro service disruptions. Reviewing 200 reports of the flood-affected infrastructure in the Tokyo (Ministry of Land 2008), Shanghai (Li et 201 al. 2018a), London (Gonzva et al. 2017), Barcelona (Saurí and Palau-Rof 2017) and New York 202 (MTA New York 2012) systems, it draws attention to considering underground system flood risk 203 assessment as a key factor in an urban resilience analysis.

204 Table 3 provides an overview of the hazards assessment approaches for metro systems in an 205 organized manner. The hazard classification mentioned at the beginning relates to the different 206 studies, with a sub-themes detailed summary for hazard category. This summary attempts to 207 highlight the differences between studies focusing on other hazards, extensive, in contrast to the lack of water-related hazards for metro systems. 


\section{Hazard}

\section{Study Approach}

\section{Classification}

\section{Airborne Particulate Matter - Air Quality}

a. Studies of the concentration of particulate matter in tunnels and station platforms at a local level

b. Air quality monitoring and prediction studies at metro stations

c. Review studies of air quality in underground metro systems

d. Studies detailing factors that affect air quality in metro stations

e. Air quality studies in metro systems carried out in developing countries

f. Numerical models of air quality in metro systems

\section{Geohazard: Ground fissures and Seismic impacts}

a. Assessment of the normal stress, shearing stress, or any deformation kind of the section of a Metro underground line

b. Effects of metro-induced ground-borne vibration

c. Investigation of the train-induced settlement of a metro tunnel in clays or permeable strata

d. Seismic response of a segmented metro tunnel with flexible joints passing through active ground fissures

e. Geotechnical conditions of deep running metro tunnels

f. Failure of metro tunnels that pass obliquely through ground fissures at low angles

g. Countermeasures to mitigate the adverse impact caused by the activity of ground fissure

\section{Geohazard: Groundwater flows}

a. A method used to predict time-dependent groundwater inflow into a metro tunnel

b. Methods used for evaluation of steady-state groundwater inflow to a shallow circular cross-section Metro tunnel

c. Impact on aquifers due to the construction of metro tunnels producing changes in the natural groundwater behaviour

d. Groundwater raising or lowering phenomenon modelling due to metro underground infrastructure

Fire and Smoke

a. Ventilation aided tunnel evacuation systems to create smoke-free evacuation passageway out of the tunnels

b. Assessment of the evacuation of passengers in a metro fire event

c. Risk analysis frameworks for fire safety in underground metro systems

d. Infrastructure of vehicles for passengers' life safety facing challenges from fires in metro stations

e. Conditions into metro stations during fire events

\section{Reviewed Sources}

\section{Papers}

(Cheng et al. 2008; Kam et al. 2011; Querol et al. 2012; Cartenì et al. 2015; Cusack et al. 2015; Perrino et al. 2015; Qiao et al. 2015; Li et al. 2018b; Cartenì and Cascetta 2018)

(Kim et al. 2010, 2012, 2017)

(Carteni 2016; Hwang et al. 2017; Xu and Hao 2017; Moreno et al. 2018)

(Moreno et al. 2014, 2015a; Martins et al. 2015, 2016; Li et al. 2018b)

(Murruni et al. 2009; Mugica-Álvarez et al. 2012)

(López González et al. 2014; Qiao et al. 2015; Moreno et al. 2015a)

\section{Papers}

(Huang et al. 2014; Shi et al. 2018)

(Wu and Xing 2018)

(Di et al. 2016; Huang et al. 2017a; Tang et al. 2017)

(Liu et al. 2017)

(Dashko 2016; Wu et al. 2018c)

(Peng et al. 2016)

(Wang et al. 2016)

6 Papers

(Liu et al. 2018)

(Nikvar Hassani et al. 2018)

(Font-Capo et al. 2015)

(Raben-Levetzau et al. 2004; Gattinoni and Scesi 2017; Colombo et al. 2018)

See Notes

(Gao et al. 2013; Liu et al. 2019)

(Zhong et al. 2008; Wang et al. 2013; Lo et al. 2014; Song et al. 2018)

(Soons et al. 2006; Wu et al. 2018b)

(Li and Dong 2011; Wang et al. 2018)

(Gu et al. 2016) 


\section{Water-related hazards: Floods due to extreme rainfall or due to river floods}

a. Connection linking flood events on the surface with vulnerability to flooding of underground subway infrastructure.

b. Frameworks based on decision-making methods as networks theory and analytic hierarchy process for assessing the flood evolution process and consequences in underground spaces

c. Integration of a stormwater management model into a geographical information system to evaluate the flood risk in a specific metro system

d. Methodologies to obtaining risk level studying both flood intensity and evacuation difficulty in underground spaces like metro stations

e. Analysis of metro systems resilience in the face of flood hazards, studying the components failure steps

f. Risk assessment for metro systems flooding events based on regional flood risk evaluation methods

g. Evaluation of the waterlogging risk of metro infrastructure caused by rainstorm in a specific Metro system

h. Assessment of the risk in a specific metro system against fluvial flooding

i. Evacuation of ridership from inundated underground space

\section{Papers}

(Lyu et al. 2016)

(Lyu et al. 2018; Wu et al. 2018a)

(Herath and Dutta 2004; Li et al. 2018a; Lyu et al. 2019a)

(Han et al. 2019)

(Gonzva et al. 2017)

(Lyu et al. 2019b)

(Quan et al. 2011)

(Compton et al. 2009)

(Ishigaki et al. 2008, 2010)

Table 3. Literature review on hazards affecting metro systems worldwide 


\section{Discussion and future research directions}

211 Resilience concept for public transport systems involves ensuring service availability through 212 operation quality and integrated connectivity with the city transport network. The vulnerability of 213 transportation systems is quantified by the transportation network efficiency when nodes, or in 214 this case, metro stations, suffers service disruptions (Zhang et al. 2018).

215 Metro systems resilience improvements have focused on examining transport networks efficiency 216 and return times to normal conditions following mathematical models, irrespective of particular 217 risk management and its importance for metro systems resilience improving, understood as the 218 system's resilience.

219 Studies such as that conducted by Avci and Ozbulut (2018) present a simplified approach to 220 hazard and vulnerability risk assessment for metro stations; focus on setting the overall 221 assessment for each metro system component, but not on how the various hazards may affect the 222 system as a whole. Although each metro system and station are diverse, the risks caused by 223 different hazards change in magnitude and importance according to the hazard impacting the metro service.

225 Decision-makers commit to ensuring the viability of their public transport systems, and that viability entails a priority interest in the system essential operation under normal operating conditions. Geotechnical hazards influence these operational conditions because they involve natural situations such as groundwater intrusion and tunnel fissures, as hazards related to the operation of the system, such as the generation of particulate matter and fires caused by electrical failures.

Metro systems hazards classification into five categories by scientific research examine a broad studies spectrum focus on metro stations air quality and the geotechnical hazards that underground infrastructure must control.

Because of the increased frequency and intensity of events associated with these hazards, researchers have focused their efforts on them. Incidents such as fires and the presence of smoke, as physical geotechnical circumstances such as earthquakes, significantly affect ridership of metro's underground networks due to the high prevalence of loss of human life in such events, severe damage to existing infrastructure, and dangerous effects for ridership health. Advanced metro systems consider risk management in their processes due to internal system conditions such as equipment or infrastructure maintenance, and its interest nowadays is focusing on extreme weather and climate change hazards, because these event types higher forecasted frequency. An influential example is TfL, Transport for London, system admin who has established action plans for managing extreme weather events (Transport for London 2011). 
244 Researchers have not addressed the water-related hazards in the metro systems in much detail. As

245 Willems et al. (2012) argued, vulnerability increases, urban flooding and sewerage surcharge

246 hazards do due to climate parameters variabilities like extreme rainfall and temperatures.

247 Despite the many events, most hazard research is performed by China and Japan, due to massive 248 floods occurrence in metro systems such as Shanghai (Deng et al. 2016; Huang et al. 2017b) and 249 Osaka (Hamaguchi et al. 2016; Terada et al. 2017; Sugimoto et al. 2018) metro systems.

250 United Nations Global Assessment Report (GAR) 2019 report (UNDRR 2019) indicates urban 251 areas global disasters in 1985 and 2015 were triggered by water-related hazards, except in North 252 America. The UN concludes that localized hazards, including flash floods, urban flooding and 253 other weather-specific events, are responsible for extensive damage to infrastructure and 254 livelihoods, representing the highest economic losses and impact on development assets such as 255 metro infrastructure (UNDRR 2019).

256 While hydrological hazards studies are a growing field, to date, relatively little research on floods 257 affecting metro systems exists. The lack of climate change-related hazards studies on metro 258 systems is worrisome.

\section{6. Conclusion}

260 This Literature review provides a better understanding of hazards and vulnerabilities in metro 261 systems in four novel ways. First, it presents urban population growth and its intrinsic relationship with hazards in transport systems, focusing on the metro system as city backbone.

263 Second, it emphasizes the interdependence between public transport services and other services provided in a city, which leads to increased resilience once have services interconnection. Metro systems represent an essential link in urban transport management, and as part of the chain , in particular, lacks a summary of the potential hazards that can disrupt their operation.

267

Third, it presents a potential hazards summary metro systems can experience, categorizing into four classes, identifying one (water-related) as an insufficient studied in-depth hazard type, in comparison to the other three types known.

270 Fourth, it offers an alternative concept concerning metro systems hazards assessment, beyond the conventional view, reflects improving resilience by not just time reduce connecting another transportation node, also proposes hazards mitigation, boosting system resilience.

273 As the gap identified in this study, we recognized a lack of scientific information of the waterrelated hazards affecting metro systems. One of the expected developments from this research is

275 to help inform future developments in water-related hazards as a fundamental component in understanding all the hazards that can affect underground transport systems. 


\section{Acknowledgments}

278 The authors thank the RESCCUE project, which is funded by the EU H2020 (Grant Agreement 279 No. 700174), whose support is gratefully acknowledged.

\section{References}

281

Avci O, Ozbulut O (2018) Threat and vulnerability risk assessment for existing subway stations: A simplified approach. Case Stud Transp Policy 6:663-673. doi: 10.1016/j.cstp.2018.08.005

Carteni A (2016) Particulate matter concentrations in urban metro systems: Case studies and a literature review. In: EEEIC 2016 - International Conference on Environment and Electrical Engineering. IEEE, pp 1-6

Cartenì A, Cascetta F (2018) Particulate matter concentrations in a high-quality rubber-tyred metro system: the case study of Turin in Italy. Int J Environ Sci Technol 15:1921-1930. doi: 10.1007/s13762-017-1566-x

Cartenì A, Cascetta F, Campana S (2015) Underground and ground-level particulate matter concentrations in an Italian metro system. Atmos Environ 101:328-337. doi: 10.1016/j.atmosenv.2014.11.030

Chen C, Ibekwe-SanJuan F, Hou J (2010) The structure and dynamics of cocitation clusters: A multiple-perspective cocitation analysis. J Am Soc Inf Sci Technol 61:1386-1409. doi: 10.1002/asi.21309

Cheng YH, Lin YL, Liu CC (2008) Levels of PM10 and PM2.5 in Taipei rapid transit system. Atmos Environ 42:7242-7249. doi: 10.1016/j.atmosenv.2008.07.011

Colombo L, Gattinoni P, Scesi L (2018) Stochastic modelling of groundwater flow for hazard assessment along the underground infrastructures in Milan (northern Italy). Tunn Undergr Sp Technol 79:110-120. doi: 10.1016/j.tust.2018.05.007

Compton KL, Faber R, Ermolieva TY, et al (2009) Uncertainty and disaster risk management: modeling the flash flood risk to Vienna and its subway system

Cusack M, Talbot N, Ondráček J, et al (2015) Variability of aerosols and chemical composition of PM 10 , PM 2.5 and PM 1 on a platform of the Prague underground metro. Atmos Environ 118:176-183. doi: 10.1016/j.atmosenv.2015.08.013

D’Lima M, Medda F (2015) A new measure of resilience: An application to the London Underground. Transp Res Part A Policy Pract 81:35-46. doi: 10.1016/j.tra.2015.05.017

Dashko R (2016) Geotechnical analysis of long-term stability of Saint Petersburg metro tunnels in upper Vendian clay. In: 15th International Multidisciplinary Scientific GeoConference SGEM2015, Science and technologies in geology, exploration and mining

Deng JL, Shen SL, Xu YS (2016) Investigation into pluvial flooding hazards caused by heavy rain and protection measures in Shanghai, China. Nat. Hazards 83:1301-1320

Di H, Zhou S, Xiao J, et al (2016) Investigation of the long-term settlement of a cut-and-cover metro tunnel in a soft deposit. Eng Geol 204:33-40. doi: 10.1016/j.enggeo.2016.01.016

Eckhardt D, Leiras A, Thomé AMT (2019) Systematic literature review of methodologies for assessing the costs of disasters. Int J Disaster Risk Reduct 33:398-416. doi: 10.1016/J.IJDRR.2018.10.010 
Evans B, Chen AS, Prior A, et al (2018) Mapping urban infrastructure interdependencies and fuzzy risks. Procedia Eng 212:816-823. doi: 10.1016/j.proeng.2018.01.105

Font-Capo J, Pujades E, Vàzquez-Suñé E, et al (2015) Assessment of the barrier effect caused by underground constructions on porous aquifers with low hydraulic gradient: A case study of the metro construction in Barcelona, Spain. Eng Geol 196:238-250. doi: 10.1016/j.enggeo.2015.07.006

Gao R, Li A, Lei W, et al (2013) A novel evacuation passageway formed by a breathing air supply zone combined with upward ventilation. Phys A Stat Mech its Appl 392:4793-4803. doi: 10.1016/j.physa.2013.06.030

Gattinoni P, Scesi L (2017) The groundwater rise in the urban area of Milan (Italy) and its interactions with underground structures and infrastructures. Tunn Undergr Sp Technol 62:103-114. doi: 10.1016/j.tust.2016.12.001

Gonzva M, Barroca B, Gautier PÉ, Diab Y (2017) Modeling disruptions causing domino effects in urban guided transport systems faced by flood hazards. Nat Hazards 86:183-201. doi: 10.1007/s11069-016-2680-7

Gu SN, Zhu GQ, Zan WX (2016) Numerical Study on Transverse Temperature Distribution of Fire Zone in Metro Tunnel Fire. In: Procedia Engineering. pp 376-383

Haghshenas H, Vaziri M (2012) Urban sustainable transportation indicators for global comparison. Ecol Indic 15:115-121. doi: 10.1016/j.ecolind.2011.09.010

Hamaguchi S, Ishigaki T, Shimada H, et al (2016) Underground inundation by storm surge caused by super typhoon. J Japan Soc Civ Eng Ser B1 (Hydraulic Eng 71:I_1387-I_1392. doi: 10.2208/jscejhe.71.i_1387

Han Y, Shin E, Eum T, Song C (2019) Inundation risk assessment of underground space using consequenceprobability matrix. Appl Sci 9:1196. doi: 10.3390/app9061196

Herath S, Dutta D (2004) Modeling of urban flooding including underground space. In: 2nd APHW conference 5-8 July 2004 Singapore /Asia Pacific Association of Hydrology and Water Resource. pp 1-9

Huang Q, Huang H wei, Ye B, et al (2017a) Dynamic response and long-term settlement of a metro tunnel in saturated clay due to moving train load. Soils Found 57:1059-1075. doi: 10.1016/j.sandf.2017.08.031

Huang Q, Wang J, Li M, et al (2017b) Modeling the influence of urbanization on urban pluvial flooding: a scenariobased case study in Shanghai, China. Nat Hazards 87:1035-1055. doi: 10.1007/s11069-017-2808-4

Huang W, Liu D, Jiang H (2014) Analytical solution of stresses on lining structure of Xi'an metro crossing ground fissure with $30^{\circ}$. Electron J Geotech Eng 19 M:2899-2907

Hwang SH, Park WM, Park JB, Nam T (2017) Characteristics of PM 10 and CO 2 concentrations on 100 underground subway station platforms in 2014 and 2015. Atmos Environ 167:143-149. doi: 10.1016/j.atmosenv.2017.08.019

Ishigaki T, Asai Y, Nakahata Y, et al (2010) Evacuation of aged persons from inundated underground space. Water Sci Technol 62:1807-1812. doi: 10.2166/wst.2010.455

Ishigaki T, Onishi Y, Asai Y, et al (2008) Evacuation criteria during urban flooding in underground space. 11th Int Conf Urban Drain 7

Kam W, Cheung K, Daher N, Sioutas C (2011) Particulate matter (PM) concentrations in underground and groundlevel rail systems of the Los Angeles Metro. Atmos Environ 45:1506-1516. doi: 
Kim D, Lim U (2016) Urban resilience in climate change adaptation: A conceptual framework. Sustain 8:405. doi: 10.3390/su8040405

Kim M, Park S, Namgung HG, Kwon SB (2017) Estimation of inhaled airborne particle number concentration by subway users in Seoul, Korea. Environ Pollut 231:663-670. doi: 10.1016/j.envpol.2017.08.077

Kim M, Sankararao B, Kang O, et al (2012) Monitoring and prediction of indoor air quality (IAQ) in subway or metro systems using season dependent models. In: Energy and Buildings. pp 48-55

Kim YS, Kim MJ, Lim JJ, et al (2010) Predictive monitoring and diagnosis of periodic air pollution in a subway station. J Hazard Mater 183:448-459. doi: 10.1016/j.jhazmat.2010.07.045

Li M, Kwan MP, Yin J, et al (2018a) The potential effect of a 100-year pluvial flood event on metro accessibility and ridership: A case study of central Shanghai, China. Appl Geogr 100:21-29. doi: 10.1016/j.apgeog.2018.09.001

Li Y, Dong L (2011) Function design of emergency rescue vehicle in metro Fire. In: ICTE 2011. American Society of Civil Engineers, Reston, VA, pp 2946-2951

Li Z, Che W, Frey HC, Lau AKH (2018b) Factors affecting variability in PM2.5 exposure concentrations in a metro system. Environ Res 160:20-26. doi: 10.1016/j.envres.2017.09.006

Liu C, Zhong M, Tian X, et al (2019) Study on emergency ventilation for train fire environment in metro interchange tunnel. Build Environ 147:267-283. doi: 10.1016/j.buildenv.2018.10.022

Liu N, Huang Q, Ma Y, et al (2017) Experimental study of a segmented metro tunnel in a ground fissure area. Soil Dyn Earthq Eng 100:410-416. doi: 10.1016/j.soildyn.2017.06.018

Liu XX, Shen SL, Xu YS, Yin ZY (2018) Analytical approach for time-dependent groundwater inflow into shield tunnel face in confined aquifer. Int J Numer Anal Methods Geomech 42:655-673. doi: 10.1002/nag.2760

Lo SM, Wang WL, Liu SB, Ma J (2014) Using agent-based simulation model for studying fire escape process in metro stations. In: Procedia Computer Science. pp 388-396

López González M, Galdo Vega M, Fernández Oro JM, Blanco Marigorta E (2014) Numerical modeling of the piston effect in longitudinal ventilation systems for subway tunnels. Tunn Undergr Sp Technol 40:22-37. doi: 10.1016/j.tust.2013.09.008

Lyu H-M, Shen S-L, Yang J, Yin Z-Y (2019a) Scenario-based inundation analysis of metro systems: a case study in

Lyu HM, Shen SL, Zhou A, Yang J (2019b) Perspectives for flood risk assessment and management for mega-city Shanghai. Hydrol Earth Syst Sci Discuss 1-30. doi: 10.5194/hess-2019-28 metro system. Tunn. Undergr. Sp. Technol. 84:31-44

Lyu HM, Sun WJ, Shen SL, Arulrajah A (2018) Flood risk assessment in metro systems of mega-cities using a GISbased modeling approach. Sci Total Environ 626:1012-1025. doi: 10.1016/j.scitotenv.2018.01.138 Guangzhou, China. Water (Switzerland) 8:. doi: 10.3390/w8100447 system under simultaneous disruptive events. In: Procedia Computer Science. pp 42-50 
Martins V, Moreno T, Mendes L, et al (2016) Factors controlling air quality in different European subway systems. Environ Res 146:35-46. doi: 10.1016/j.envres.2015.12.007

Martins V, Moreno T, Minguillón MC, et al (2015) Exposure to airborne particulate matter in the subway system. Sci Total Environ 511:711-722. doi: 10.1016/j.scitotenv.2014.12.013

Mattsson LG, Jenelius E (2015) Vulnerability and resilience of transport systems - A discussion of recent research. Transp Res Part A Policy Pract 81:16-34. doi: 10.1016/j.tra.2015.06.002

Ministry of Land I and T (2008) Past flood cases. In: Water Manag. - Homel. Secur. http://www.mlit.go.jp/river/bousai/main/saigai/jouhou/jieisuibou/bousai-gensai-suibou01-kako.html

Mohammadi A, Amador-Jimenez L, Nasiri F (2019) Review of asset management for metro systems: challenges and opportunities. Transp Rev 39:309-326. doi: 10.1080/01441647.2018.1470119

Moher D, Liberati A, Tetzlaff J, et al (2009a) Preferred reporting items for systematic reviews and meta-analyses: The PRISMA statement (Chinese edition). J. Chinese Integr. Med. 7:889-896

Moher D, Liberati A, Tetzlaff J, et al (2009b) Preferred reporting items for systematic reviews and meta-analyses: the PRISMA statement. PLOS Med 6:e1000097

Moreno T, de Miguel E (2018) Improving air quality in subway systems: An overview. Environ. Pollut. 239:829-831

Moreno T, Martins V, Querol X, et al (2015a) A new look at inhalable metalliferous airborne particles on rail subway platforms. Sci Total Environ 505:367-375. doi: 10.1016/j.scitotenv.2014.10.013

Moreno T, Martins V, Reche C, et al (2018) Air quality in subway systems. In: Non-Exhaust Emissions. Academic Press, pp 289-321

Moreno T, Pérez N, Reche C, et al (2014) Subway platform air quality. Assessing the influences of tunnel ventilation, train piston effect and station design. Atmos Environ 92:461-468. doi: 10.1016/j.atmosenv.2014.04.043

Moreno T, Reche C, Rivas I, et al (2015b) Urban air quality comparison for bus, tram, subway and pedestrian commutes in Barcelona. Environ Res 142:495-510. doi: 10.1016/j.envres.2015.07.022

MTA New York (2012) Flood mitigation work begins on seven downtown stations. In: New York, USA. http://web.mta.info/nyct/service/FloodMitigationWorkBeginsat7DowntownStations.htm. Accessed $30 \mathrm{Apr}$ 2019

Mugica-Álvarez V, Figueroa-Lara J, Romero-Romo M, et al (2012) Concentrations and properties of airborne particles in the Mexico City subway system. Atmos Environ 49:284-293. doi: 10.1016/j.atmosenv.2011.11.038

Murruni LG, Solanes V, Debray M, et al (2009) Concentrations and elemental composition of particulate matter in the Buenos Aires underground system. Atmos Environ 43:4577-4583. doi: 10.1016/j.atmosenv.2009.06.025

Nikvar Hassani A, Farhadian H, Katibeh H (2018) A comparative study on evaluation of steady-state groundwater inflow into a circular shallow tunnel. Tunn Undergr Sp Technol 73:15-25. doi: 10.1016/j.tust.2017.11.019

Peng J, He K, Tong X, et al (2016) Failure mechanism of an underground metro tunnel intersecting steep ground fissure at low angle. Int J Geomech 17:E4016006. doi: 10.1061/(asce)gm.1943-5622.0000677

Perrino C, Marcovecchio F, Tofful L, Canepari S (2015) Particulate matter concentration and chemical composition 
Qiao T, Xiu G, Zheng Y, et al (2015) Characterization of PM and microclimate in a Shanghai subway tunnel, China. In: Procedia Engineering. Elsevier, pp 1226-1232

Quan R, Zhang L, Liu M, et al (2011) Risk assessment of rainstorm waterlogging on subway in central urban area of Shanghai, China based on scenario simulation. Proc - 2011 19th Int Conf Geoinformatics, Geoinformatics 2011 0-5. doi: 10.1109/GeoInformatics.2011.5981176

Querol X, Moreno T, Karanasiou A, et al (2012) Variability of levels and composition of PM 10 and PM 2.5 in the

Raben-Levetzau J, Markussen LM, Bitsch K, Nicolaisen LL (2004) Copenhagen Metro: groundwater control in sensitive urban areas. Tunn Undergr Sp Technol 19:522. doi: 10.1016/j.tust.2004.01.037

Rodríguez-Núñez E, García-Palomares JC (2014) Measuring the vulnerability of public transport networks. J Transp Geogr 35:50-63. doi: 10.1016/j.jtrangeo.2014.01.008

Saurí D, Palau-Rof L (2017) Urban drainage in barcelona: From hazard to resource? Water Altern 10:475-492

Sharifi A, Yamagata Y (2018) Resilience-oriented urban planning. In: Lecture Notes in Energy. pp 3-27

Shi Y-J, Xiao X, Li M-G (2018) Long-term longitudinal deformation characteristics of metro lines in soft soil area. J Aerosp Eng 31:04018080. doi: 10.1061/(asce)as.1943-5525.0000910

Song XY, Pan Y, Jiang JC, et al (2018) Numerical investigation on the evacuation of passengers in metro train fire.

Soons CJ, Bosch JW, Arends G, van Gelder P (2006) Framework of a quantitative risk analysis for the fire safety in

Spanish Research Council (2018) Improve Life: Implementing methodologies and practices to reduce air pollution of

Sugimoto K, Okuoka K, Tanikawa H (2018) Establishment of three-dimensional subway GIS data for inundation analysis in urban area. J Japan Soc Civ Eng Ser G (Environmental Res 73:I_283-I_289. doi: 10.2208/jscejer.73.i_283

Sun DJ, Guan S (2016) Measuring vulnerability of urban metro network from line operation perspective. Transp Res Part A Policy Pract 94:348-359. doi: 10.1016/j.tra.2016.09.024

Tang X-W, Gan P-L, Liu W, Zhao Y (2017) Surface settlements induced by tunneling in permeable strata: a case history of Shenzhen Metro渗透性地层中隧道施工引起的地表沉降一 以深圳地铁为例. J Zhejiang Univ A 18:757-775. doi: 10.1631/jzus.a1600522

Terada M, Okabe R, Ishigaki T, et al (2017) Subway inundation by pluvial flooding in densely urbanized area. J Japan Soc Civ Eng Ser B1 (Hydraulic Eng 72:I_1357-I_1362. doi: 10.2208/jscejhe.72.i_1357

UITP (2018) World Metro Figures 2018

UITP, Saeidizand P (2015) Urban public transport in the 21St century. 1-8 
United Nations Human Settlements Programme (2013) Planning and design for sustainable urban mobility

Velasco M, Russo B, Martínez M, et al (2018) Resilience to cope with climate change in urban areas-A multisectorial approach focusing on water-The RESCCUE project. Water (Switzerland) 10:1-11. doi: 10.3390/w10101356

461

Wan C, Yang Z, Zhang D, et al (2018) Resilience in transportation systems: a systematic review and future directions. Transp Rev 38:479-498. doi: 10.1080/01441647.2017.1383532

Wang W, He T, Huang W, et al (2018) Optimization of switch modes of fully enclosed platform screen doors during emergency platform fires in underground metro station. Tunn Undergr Sp Technol 81:277-288. doi: 10.1016/j.tust.2018.07.015

Wang X, Chen S, Zhou Y, et al (2013) Simulation on passenger evacuation under fire emergency in Metro station. In: IEEE ICIRT 2013 - Proceedings: IEEE International Conference on Intelligent Rail Transportation. IEEE, pp 259-262

Wang ZF, Shen SL, Cheng WC, Xu YS (2016) Ground fissures in Xi'an and measures to prevent damage to the Metro tunnel system due to geohazards. Environ Earth Sci 75:511. doi: 10.1007/s12665-015-5169-x

WEF, Collins A (2019) The Global Risks Report 2019 14th Edition Insight Report

Willems P, Olsson J, Arnbjerg-Nielsen K, et al (2012) Impacts of Climate Change on Rainfall Extremes and Urban Drainage Systems. PB - IWA Publishing

Wu J, Fang W, Hu Z, Hong B (2018a) Application of Bayesian approach to dynamic assessment of flood in urban underground spaces. Water (Switzerland) 10:. doi: 10.3390/w10091112

Wu J, Hu Z, Chen J, Li Z (2018b) Risk assessment of underground subway stations to fire disasters using Bayesian network. Sustain 10:. doi: 10.3390/su10103810

Wu J, Liao M, Li N (2018c) Ground subsidence along Shanghai metro line 6 by PS-InSAR method. In: International Archives of the Photogrammetry, Remote Sensing and Spatial Information Sciences - ISPRS Archives. pp $1889-1893$

Wu TX, Xing HL (2018) Assessment of the performance and effects of metro-induced ground-borne vibration for mitigation measures of resilient tracks. Proc Inst Mech Eng Part F J Rail Rapid Transit 232:1448-1463. doi: $10.1177 / 0954409717731248$

Xing Y, Lu J, Chen S, Dissanayake S (2017) Vulnerability analysis of urban rail transit based on complex network theory: a case study of Shanghai Metro. Public Transp 9:501-525. doi: 10.1007/s12469-017-0170-2

Xu B, Hao J (2017) Air quality inside subway metro indoor environment worldwide: A review. Environ. Int. 107:3346

Yang Y, Liu Y, Zhou M, et al (2015) Robustness assessment of urban rail transit based on complex network theory: A case study of the Beijing Subway. Saf Sci 79:149-162. doi: 10.1016/j.ssci.2015.06.006

Zhang D ming, Du F, Huang H, et al (2018) Resiliency assessment of urban rail transit networks: Shanghai metro as an example. Saf Sci 106:230-243. doi: 10.1016/j.ssci.2018.03.023 
